\title{
Mathematical modelling of Yacyreta-Apipe scheme on the Rio Parana
}

\author{
Le modèle mathématique de l'aménagement Yacyreta-Apipe \\ sur le Rio Parana
}

\author{
T.F. Major \\ Lahmeyer International, \\ Frankfurt, FRG
}

\author{
A. Lara \\ Harza, Lahmeyer y asociados, \\ Buenos Aires, Argentine
}

\author{
J.A. Cunge \\ SOGREAH, \\ Grenoble, France
}

Le projet concerne une section d'environ $200 \mathrm{~km}$ du Rio Parana, en Argentine. Un réservoir de $1420 \mathrm{~km}^{2}$ recueillera les eaux d'un bassin versant de $975000 \mathrm{~km}^{2}$, et stockera 16900 millions de $\mathrm{m}^{3}$. Deux évacuateurs sont conçus pour évacuer $95000 \mathrm{~m}^{3} / \mathrm{s}$. Un barrage de compensation stockera $2180 \mathrm{Mm}^{3}$, avec une surface de $800 \mathrm{~km}^{2}$. Le débit turbiné sera compris entre 14000 et $21000 \mathrm{~m}^{3} / \mathrm{s}$

L'article décrit le projet et le modèle d'écoulement CARIMA (principe, construction, étalonnage, utilisation).
The project concerns a section of approximately $200 \mathrm{~km}$ of the Rio Parana in Argentina. A $1420 \mathrm{~km}^{2}$ reservoir will collect the waters of a $975,000 \mathrm{~km}^{2}$ catchment area and will store 16.900 million $m^{3}$. Two spillways are designed for a flood flow of $95.000 \mathrm{~m}^{3} / \mathrm{s}$. A compensating dam will store $2180 \mathrm{Mm}^{3}$ with a surface area of $800 \mathrm{~km}^{2}$. The operating discharge of the hydropower plant will be between 14,000 and $21.000 \mathrm{~m}^{3} / \mathrm{s}$

The paper describes the project and the CARIMA flow model (design, construction, calibration, use).
The project

The section of the Rio Parana covered by the study extends over about $200 \mathrm{~km}$ between the towns of Posadas $(\mathrm{km} \mathrm{1585)}$ and Ita Ibate $(\mathrm{km} \mathrm{1380)}$. The latter is situated about $150 \mathrm{~km}$ upstream of the confluence with the Rio Paraguay. The Yacyreta project site is roughly in the middle of the section, just upstream of the town of Ituzaingo. The catchment area of the Rio Parana upstream of the reservoir covers $975000 \mathrm{~km}^{2}$. The surface area of the reservoir will be $1420 \mathrm{~km}^{2}$ at the normal operating level of 82 m.a.s.l. The corresponding storage volume is $16900 \mathrm{Mm}^{3}$. Two spillways are designed for a flood of $95000 \mathrm{~m}^{3} / \mathrm{s}$.

The prospective compensating dam will impound a reservoir of a storage volume of $2180 \mathrm{Mm}^{3}$. The surface area of the reservoir will be $800 \mathrm{~km}^{2}$ at the normal operating level of 59 m.a.s.l.

The operating discharge of the hydropower plant will be in the range of 14000 to $21000 \mathrm{~m}^{3} / \mathrm{s}$ depending on the results of studies in progress. Continuity of navigation will be ensured by a navigation lock incorporated in the dam complex.
The Rio Parana divides into two parts about $23 \mathrm{~km}$ downstream of Posadas, into the Brazo Principal and Ana-Cua (Fig. 1). Each of these branches forms a looped network of channels separating numerous islands at least during low flow periods. The San Josemi arm connects the two main branches downstream of the main damsite. During floods substantial flow exchange can occur across the flood plain between the two main branches.

The main structure located between Guardia-Cue (main branch) and Stanquievic (Ana-Cua branch) consists of :

- left-bank dyke joining the natural high points and closing off small depressions;

- dam including the power plant at Guardia-Cue section, the navigation lock and the main branch spillway;

- dyke across the floodable part of the Yacyreta island opposite San Antonio, then following the crest corresponding to the maximum flood level;

- flood spillway on the Ana-Cua branch upstream of Stanquievic;

- dyke running on the right bank up to San Cosme.

The prospective compensating dam will be located at Ita Ibate including a navigation lock, flood spillway and closure dyke. 


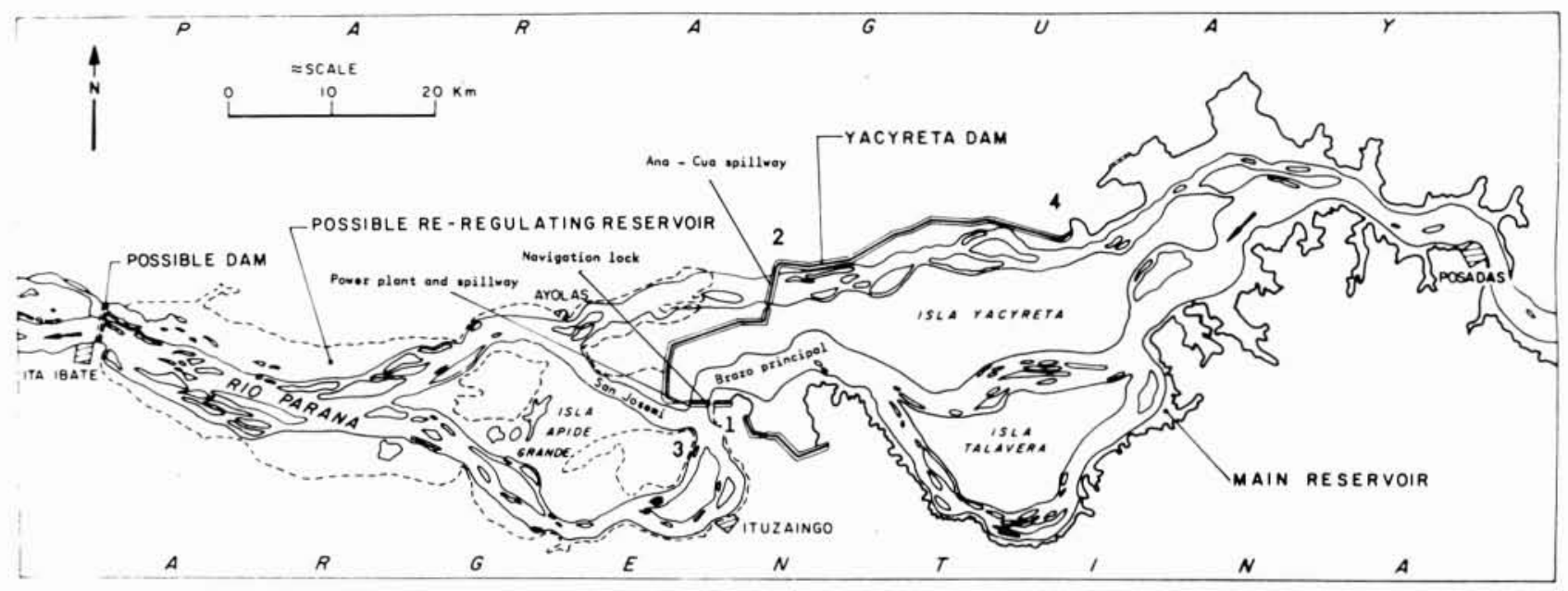

Figure 1. - Implementation of the Yacyreta Project

(1) Guardia-Cue (2) Stanquievic (3) San Antonio (4) San Cosme
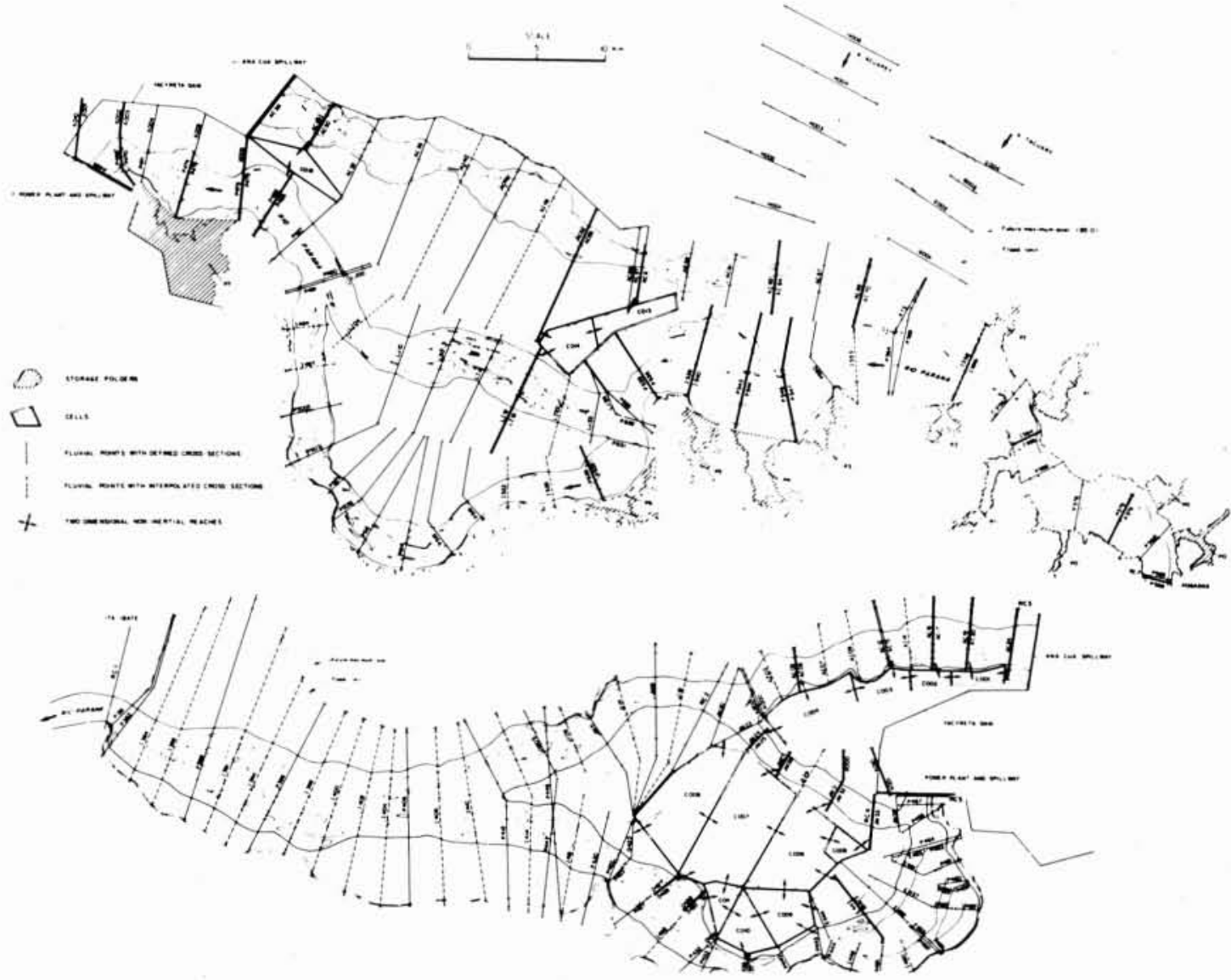

Figure 2. - Computational elements 


\section{Flow modelling by CARIMA}

The system CARIMA (CAlcul RIvière MAillé) is a simulation tool for investigation of the effects of natural or man-made modifications of river/flood plain features on flood propagation or steady flow through a particular river system developed by SOGREAH in years 1966 through 1977 which combines in a simple structure several traditional calculation techniques and a few new features which have recently been developed, (Ref. 1, 2). The design objectives of the system were :

1) To be capable of treating a model which contains both full-equation inertial channel flow and non-inertial flood plain storage and flow with no fundamental restrictions on the ways on which the two flow regimes may physically be linked.

2) To allow the user to schematise his model without having to worry about its topologic make up and calculation sequence, i.e., to add reaches which cause the branched model to become looped.

3) To provide a high level of automatic data cheeks, convenient correction and modification of model parameters, and flexibility of memory use and filing.

There are generally two flow regimes treated by CARIMA :

i) one-dimensional channel flow (1-D), in which the full flow equations are considered and

ii) two-dimensional flood plain flow (2-D) for which non-inertial channel and weir flow equations are used. One-dimensional flow is modelled by a series of computational points along the river, each of which corresponds to a measured or assumed cross-section. These points are linked by one-dimensional computational reaches over which the average section properties at either end are assumed to govern the flow. These reaches may form a looped structure, e.g., flow division around large islands, river cutoff, interconnected delta channels etc. Two-dimensional flow on the flood plain is modelled by a series of interconnected cells, for which the relation between storage volume and water surface elevation is known or assumed. Cell locations and links between cells are chosen so as to follow natural features (roads, dykes, etc.). The flow between cells is assumed to obey either a resistance-type (Manning, Strickler) or a weir type law.

A detailed description of the computational method including its numeric and algorithmic aspects may be found in Ref. 2. The CARIMA system enables to build a model of any complexity by means of the following elements :

- one-dimensional (1-D) calculation point, with assigned water level and discharge varying with time, hydraulically defined by its geometric cross sectional shape and roughness characteristics as a function of elevation;

- nodal-point (1-D), a fictitious point of confluence of different sections;

- two-dimensional (2-D) cell, a storage cell with assigned water level varying with time, defined by the area of water surface in function of elevation;

- Two-dimensional (2-D) point, a calculation point with assigned water level varying with time.
These elements may be linked by :

- one-dimensional reach, which connects two consecutive one-dimensional fluvial points. This type may either be a real (river-type reach or weir) when connecting two calculation points or fictitious when connecting a calculation point with a nodal point. A one-dimensional link is defined by the names of the points connected (upstream and downstream), length of the reach and the coefficient of weighting of the head losses in the reach;

- two-dimensional fluvial link with assigned discharge varying with time, which connects two (2-D) cells, or a cell with a fluvial point in which the flow is river type. The flow in two-dimensional links is assumed to be inertialess. For definition of two-dimensional links analogous data as for one-dimensionals have to be supplied;

- weir links, one and two-dimensional type, allow flow simulations which do not obey Strickler's law. It is, thus, possible to represent natural sills in the river bed and flow over dykes, roads or dunes. Such links are mainly used to join two-dimensional cells between themselves or with one-dimensional fluvial points.

The nodal points are only used to associate (1-D) points or simple (2-D) points (confluences). A (2-D) cell may serve as a node, but a cell can be attached to a nodal point only through the intermediary of a simple (2-D) point.

\section{Construction of the model}

A « standard " for spacing of computational points mainly depends on two conditions :

i) propagation time of small waves and hence the depth of water,

ii) the computational time step, $\Delta t$. In order to avoid numerical errors in the calculation of steep waves (especially during the operating phase) it is appropriate to choose a relationship $\Delta x / \Delta t$ as close as possible to the wave celerity $\sqrt{g h}$. Since the overall computational time step was estimated to be in the order of 2.5 minutes, depending on mean depth, the invervals between the definition points $\Delta x$ upstream and downstream of the damsite result as $3500 \mathrm{~m}$ and $2500 \mathrm{~m}$ respectively. These intervals, calculated for the future operating phase, are likewise valid for simulation of the natural conditions too; since the water depths are then less but the time step is greater (from 1 to 6 hours) whereas the water level variations are slow. It was essential to arrive at optimal spacing at the outset of the study to avoid laborious modifications in the course of the computations.

Calculation points are initially defined at each point with one or more particular characteristics :

- points with stage-discharge relationship;

- points with flood recorder;

- sites of future man-made structures (dam, spillway, power plant):

- singular head-loss sections (natural sills, narrows);

- points corresponding to storage polders;

- boundaries (Posadas, Ita Ibate) and the upstream

boundaries of tributaries;

- confluences and bifurcations;

- measured cross-sections. 

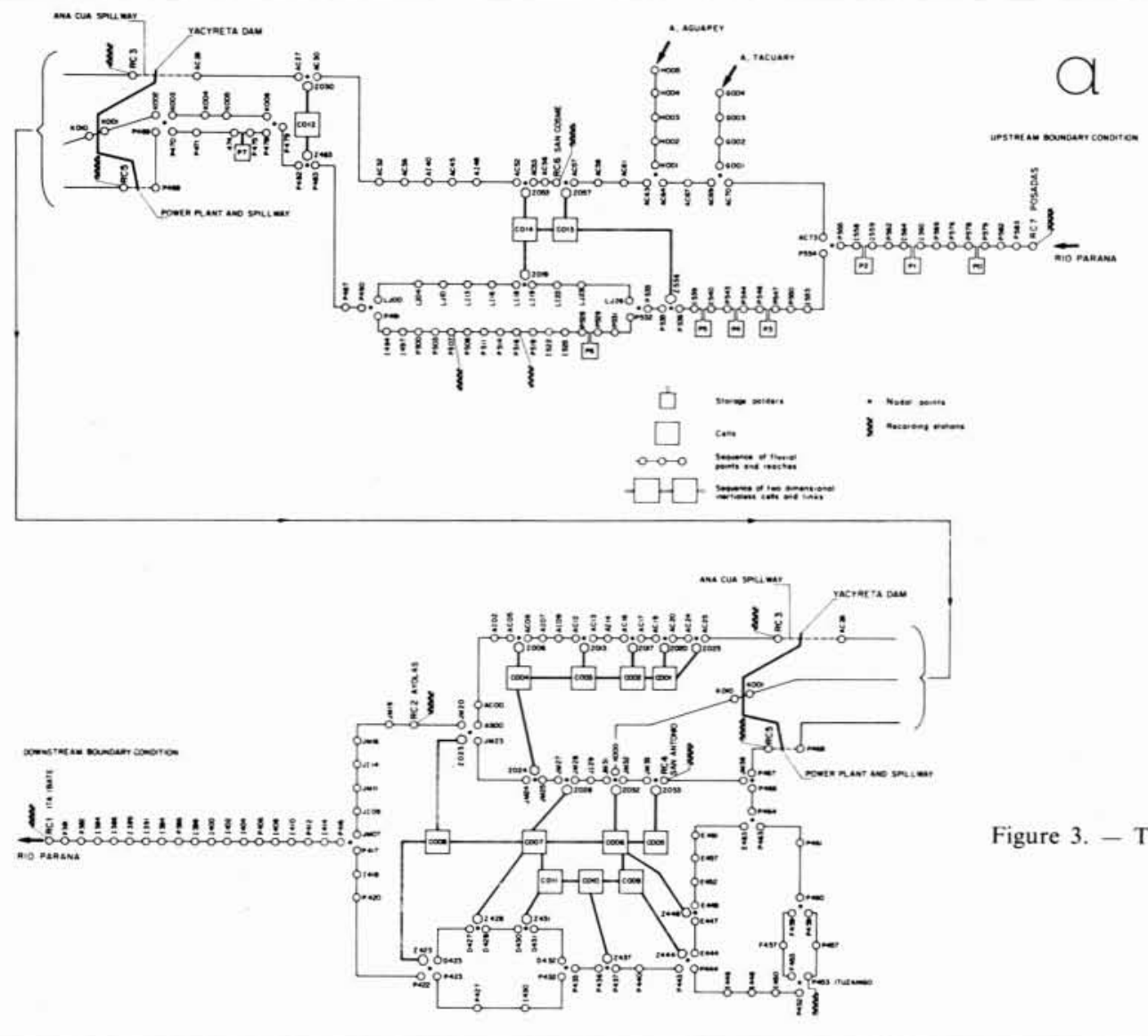

Figure 3. - Topologic scheme

The intervals between the above points are further divided into reaches the length of which corresponds the wave propagation criterion.

Areas in which the inertia term is not taken into account are divided into two-dimensional cells delimited on Fig. 2 according to the topography and the direction of flows. Exchanges between cells are materialised on the diagrams by double arrows. Links between one-dimensional and two-dimensional parts of the model are also represented by double arrows. The storage polders linked with the one-dimensional part are represented by hatching. Some of them with small surface area are grouped together and attached to the same calculation points (basins P0, P1 and P2).

All the elements defined above may be represented by a topological scheme clearly showing the complexity of the network (Fig. 3). The locations of the various features can easily be found by referring to Fig. 2. The links indicated by dotted lines on the topological scheme correspond to those features which will be changed between the phase of study of natural conditions and the subsequent operational phases. The main structure is materialised by a thick line. The model comprises 284 calculation points and 310 links.

Upstream of the power plant, if the slight variations of water level across the width of the reservoir are neglected, the flow could virtually be considered as one-dimensional. The simplest way would be, since the islands will be well submerged, to build a one-dimensional model. Such a solution would, however, not allow simulation of the natural state in which the flow is divided into several channels separated by submersible islands. Since the main structure will include two flood spillways, each of which discharges into a separated river branch, it would be necessary to provide for two distinct outflows with imposed time-dependant discharges. This is rather complex on one-dimensional basis. Due to these reasons, it was decided to build a model which makes possible a flow simulation in a looped river systems containing onedimensional channel flow with inertial term and twodimensional flood plain flow, or flow in submersible areas, for which the inertial term can be neglected.

To facilitate easy passage from natural conditions to future operation, the following constraints have to be taken into account :

- a short reach is provided for at the site of each structure, these will initially be ordinary river reaches for study of the natural state, and will subsequently be modified to incorporate the laws of operation of the structures;

- areas which are not subject to flooding in the natural state but will be submerged in future conditions are represented with the precautions necessary to avoid difficulties in calculation when they dry out due to falling of reservoir levels.

The character of phenomena necessitates for the future reservoir a careful choice of separating lines between each of the branches. This choice was based on detailed analysis of the topography of flood plains. 
The portion immediately upstream of the damsite is simulated by two parallel channels, first, the sequences of computational points $\mathrm{P} 467$ to $\mathrm{P} 478$, and second, the sequence K000 to K006 which represents the flood plain. This representation may cause difficulties in calculation under low flow conditions, since the flood plain dries out. To avoid this, a fictitious trench of adequate depth and of negligible width, being continuously supplied by a very small discharge, was added. The branches are linked by nodes at two locations : K002 - K003 - P470 - P469 and further upstream at K006 - P479 - P478. The purpose of these links is to obtain free surface elevation equalization during the exploitation runs.

The upstream Ana-Cua branch, which will incorporate the Ana-Cua flood spillway is modelled one-dimensionally together with its right-bank flood plain. The two upstream tributaries Aquapey and Taycuary are represented by one-dimensional fluvial points. The remaining small tributaries are modelled as storage polders, defined by the two consecutive fluvial points between which the basins are situated and by the corresponding area of water surface in function of elevation. The storage polders are assumed to fill and empty in accordance with level variation in the river without time lag.

By two-dimensional cells are modelled the following flood plains :

i) the area near San Cosme which is located above the most of flood levels - it will however be submerged by the reservoir - enables exchanges with the surrounding areas through $\mathrm{C} 013$ and $\mathrm{C} 014$, and

ii) the narrow strip separating Ana-Cua from the main branch makes possible the reproduction of flow exchanges through $\mathrm{C} 012$ which occur when flow exceeds $20000 \mathrm{~m}^{3} / \mathrm{s}$.

Downstream of the site of main structures one-dimensional modelling is favored by a complex network of channels in which the main channel P... and the secondary branches F..., E..., J... and A... are in particular distinguished. In the downstream portion below the confluence of all branches the numerous islands and marshy flood plains are taken into account by varying the roughness coefficients of cross sections. Since one-dimensional modelling was expected to be more effective for flow conditions with the future compensating reservoir, a sophisticated looped schematisation was abandoned.

By two-dimensional cells are treated :

i) the flood plain on the left bank of Ana-Cua parallel to this branch because of the observed flow exchange between the flood plain, Ana-Cua and the San Josemi branches (C001-C002-C003-C004), and

ii) the Apipe-Grande island, which rises vertically above the water surface profile of the future compensating reservoir (CO05 through C011).

As for most of the models of this type the number of surveyed cross sections was not sufficient for a proper model construction. It was, therefore, necessary either to interpolate between known sections or attribute to certain calculation points -after corrections of altitude- cross sections which are in some cases remote from the calculation point. This is the case of the entire downstream part between the points $\mathrm{P} 416$ to $\mathrm{RCl}$. A cross section attributed to a calculation point is made up of several sub-sections of the low-water and high-water beds. The division into sub-sections depends on the geometry and roughness characteristics. The definition of each sub-section requires a detailed analysis of data and constitutes the major task at this stage of model construction.

For reaches with flood plain if a surveyed cross section is not quite representative for the reach, a width correction is applied. The correction coefficient is derived from the relationship between the width measured on the known cross section and the computational width. The latter is calculated on the basis of the planimetric survey of the area to be represented by the calculation point and the length of the corresponding reach (along the chosen alignment). This time consuming but for correct simulation of wave propagation indispensable calculation is repeated for each known level.

Short one-dimensional reaches are defined at the site of main structures such as the power plant, the main branch and the Ana-Cua branch spillways with codes which will give access to standard CARIMA routines to operate these structures. The reach corresponding to the closure dyke opposite the calculation point $\mathrm{RC} 4$ will then be replaced by an insubmersible weir simulating the dyke.

Two-dimensional fluvial links are defined between the cells $\mathrm{C} 005-\mathrm{C} 006$ and $\mathrm{C} 013-\mathrm{C} 014$. Apart from these, all links in the two-dimensional part of the model are of weir type. The computation procedure provides for operation of these weirs in both directions and distinguished between free and submerged flows. The most important one-dimensional type weir link is situated in the Ana-Cua branch between fluvial points AS00-AC00 where supercritical flow may occur under low flows.

The initial selection of roughness coefficients was based on

i) classification of the model into reaches with identical roughness characteristics,

ii) examination of soil characteristics and vegetation.

Seven types of roughness were retained:

- for low water bed of various branches : sand, rock, shrubs

- for the flood plains : sand, grass, shrubs, marshes.

In the course of the model adjustment (calibration) it was necessary to correct or modify the above values at numerous calculation points to allow for unidentified bed irregularities and the effects of islands. Table 1 summarizes the roughness coefficients obtained after adjustment of the model.

Table 1 - Finally adopted Strickler's roughness coefficients

\begin{tabular}{|c|c|c|c|c|c|c|c|c|}
\hline \multirow[b]{2}{*}{ Model } & \multirow[b]{2}{*}{ reach } & \multicolumn{3}{|c|}{ River bed } & \multicolumn{2}{|r|}{ F1ood } & \multicolumn{2}{|c|}{ valley } \\
\hline & & is sand & rock & shrubs & shrubs & Tgrass & sand & Tmarshes \\
\hline & & & & & & & & \\
\hline RC7 & - P555! & 32 & 35 & 15 & 15 & 20 & 32 & 25 \\
\hline P554 & - P519| & 32 & 35 & 15 & 15 & 20 & 32 & 25 \\
\hline P516 & - P4911 & 32 & 35 & 15 & 15 & 20 & 32 & 25 \\
\hline P490 & - P468 & 20 & 20 & 15 & 15 & 20 & 20 & 25 \\
\hline $\mathrm{AC} 73$ & - ACOOI & 28 & 30 & 13 & 13 & 17 & 28 & 22 \\
\hline LJ 26 & - LJOOI & 32 & 35 & 15 & 15 & 20 & 32 & 25 \\
\hline$K 006$ & - K000 & 32 & 35 & 15 & 15 & 20 & 32 & 25 \\
\hline G004 & - G001 & 32 & 35 & 15 & 15 & 20 & 32 & 25 \\
\hline H005 & - H0011 & 32 & 35 & 15 & 15 & 20 & 32 & 25 \\
\hline RC5 & - P4171 & 32 & 35 & 15 & 15 & 25 & 32 & 25 \\
\hline JM36 & - JM23 & 32 & 35 & 15 & 15 & 20 & 32 & 25 \\
\hline JM2O & - JM071 & 45 & 25 & 10 & 10 & 10 & 25 & 10 \\
\hline P416 & - $\mathrm{RCl}$ & 25 & 25 & 10 & 10 & 10 & 25 & 10 \\
\hline & & & & & & & & \\
\hline
\end{tabular}




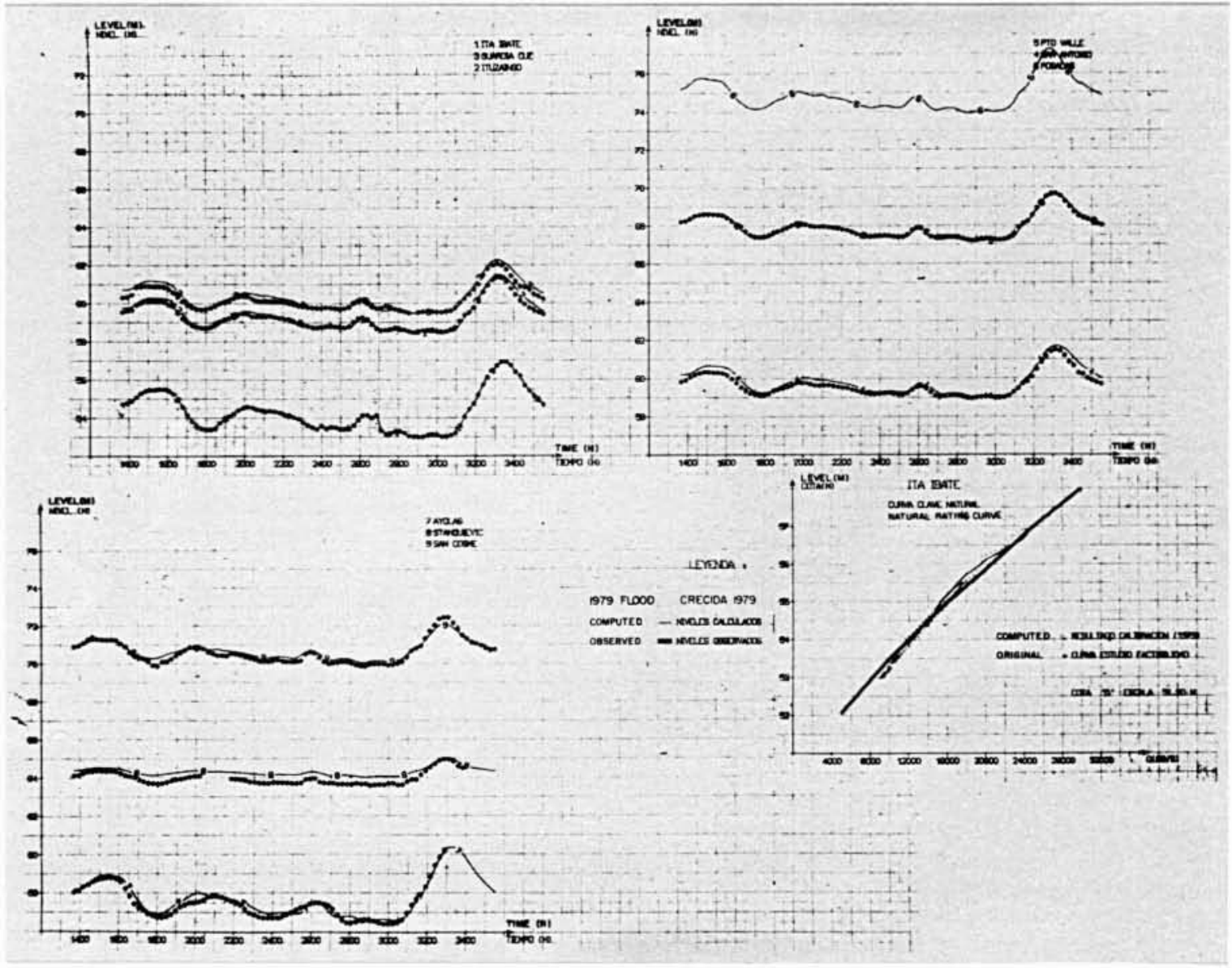

Figure 4. - Calibration of the 1979 Flood

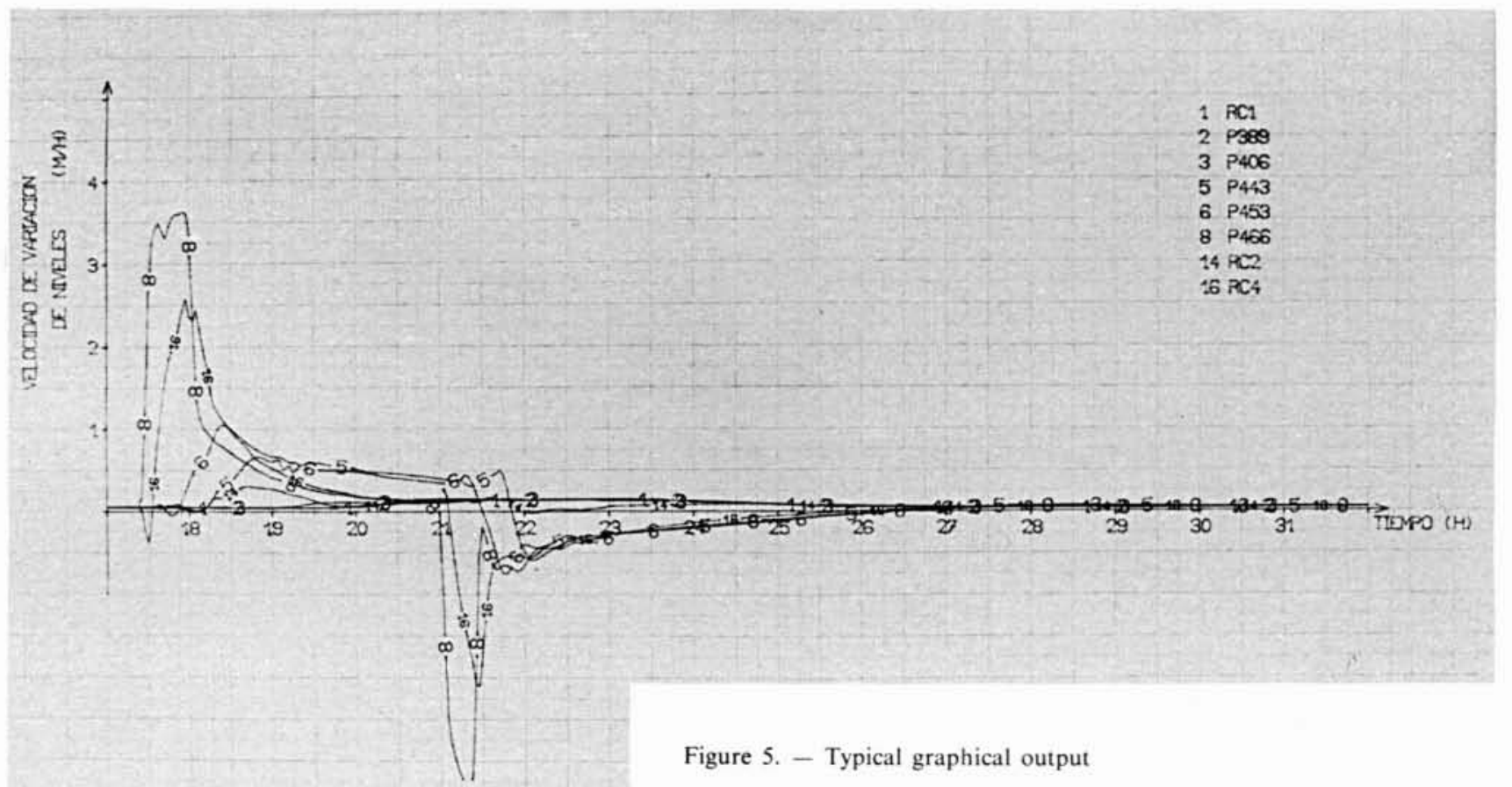

Figure 5. - Typical graphical output 


\section{Model calibration}

During the first test of adjustment the roughness coefficients were modified within physically reasonable limits. When the required fit between observed and computed water surface profiles and flows is achieved, no further adjustments are required.

Otherwise, the cause of discrepancies is to be identified which may be of topographical nature, incorrect choice of locations of calculation points, or errors in schematization. In course of steady state calibration the following modifications in the original model have been carried out :

i) roughness reduction by around $40 \%$ in the reach JM20 to JM07 which enabled adjustment of the lower part of the stage-discharge relationship at $\mathrm{RC} 2$;

ii) joining of the links between the main and Ana-Cua branches (cell C012), which altered the flow distribution between the branches for inflows greater than $20000 \mathrm{~m}^{3} / \mathrm{s}$ at $\mathrm{RC} 7$ :

iii) due to irregularities of river bed, addition of new calculation points P583 and AC56 downstream of RC7 and RC6 respectively;

iv) since the natural rocky sill across the Ana-Cua branch eliminates the downstream influence on flow under small discharges a new point $\mathrm{AS} 00$ was placed at the down-stream extremity of this branch;

v) the elevations of the weirs ensuring exchange between the main and San-Josemi branch across the island were changed (cells $\mathrm{C} 005$ and C011) based on historic flood observations.

The objective of adjustments for unsteady flow was to reproduce observed flood hydrographs at recording gauges. 12 computer runs were necessary to complete this activity, with the following main operations :

i) first, it was impossible to reproduce the stage-discharge relationships at $\mathrm{RC} 2$ and RC5 with required precision, nor was it possible to reproduce the flood hydrographs at Ituzaingo (P453) and Ayolas (RC2). The following analysis proved that the initially furnished rating curve for Ita Ibate $(\mathrm{RCl})$ was inaccurate. The simulation was then re-run with the observed flood hydrograph at $\mathrm{RCl}$ replacing the rating curve as the condition imposed at the downstream boundary of the model. Further adjustments become then possible, and based on the results new rating curve for Ita Ibate was established;

ii) because of the difficulties encountered in reproducing of the observed hydrograph at Ituzaingo (P453) the roughness of the branches E... and $F$... had to be increased, as well as those of the reach P443 through P417. The weirs linking the cells C006, C007 and C008 in the San-Josemi branch had also to be raised. After these operations the model gave flow distributions close to the observed ones in the above branches. Although this adjustment was effected only for small discharges, the model successfully reproduced the floods at Itzaingo too;

iii) the roughness of the reach RC7-P555 was increased to improve the adjustment of the $\mathrm{H} / \mathrm{Q}$ curve and the hydrograph at RC7;

iv) the roughness at $\mathrm{AC} 20, \mathrm{RC} 3$ and $\mathrm{AC} 24$ was substantially reduced for low flows so as to get closer to the given $\mathrm{H} / \mathrm{Q}$ curve for RC3.

Adjustments for unsteady flow regimes are made by simulating records of three flood episodes for which relatively complete observations were available;

- from 1. Januar through 31 March 1977

- from 1. February through 10 April 1978

- from 1. March through 25 May 1979.

Finally, for all these floods an acceptable degree of comformity between observations and calculations is achieved, as shown for the last flood in Fig. 4.

\section{Operation of the model}

After implementation of Yacyreta the navigation downstream of the dam and power plant will considerably be influenced by extreme level variations, flow-velocities and surface gradients caused by turbine manœuvres especially such as sudden turbine release or turbine closure. Hence, the formulation and investigation of the following parameters was of particular interest :

- maximum rise or fall velocity of water stage

$$
(d y / d t) \max \text { in }[\mathrm{m} / \text { hour }],
$$

- maximum instantaneous free surface slope

$$
(d y / d x) \max \text { in }[\mathrm{m} / \mathrm{km}],
$$

- maximum flow velocity

- minimum depth of flow

$$
\begin{gathered}
v_{\max } \text { in }[\mathrm{m} / \mathrm{s}], \\
h_{\min } \text { in }[\mathrm{m}] .
\end{gathered}
$$

Furthermore, by operation of the model an important question had also to be answered : beyond how many units becomes the implementation of the compensating reservoir indispensable.

Prior to simulation of the future operation the calibrated model had to be modified at the following points :

- the upstream boundary condition was moved $87 \mathrm{~km}$ further upstream to the site of the future Corpus project in order to avoid the effects of wave reflections due to manœuvres at the Yacyreta power plant;

- the short reaches defined previously, i.e., RC5-P468 (power plant and main branch spillway) and AC26-RC3 (Ana-Cua branch spillway) were replaced by conditions of discharge as a function of time or reservoir level imposed as a function of time. These conditions were then simulated by CARIMA's standard routines. The variation of turbine discharge was treated by an external routine reproducing the opearting instructions of turbines; - the fluvial reach $\mathrm{K} 001$ through $\mathrm{K} 010$ was replaced by an insubmersible weir to simulate the dyke as a part of the main dam.

The upstream boundary condition was described by discharge as a function of time. The downstream boundary at Ita Ibate was given by stage discharge law - in absence of the compensating reservoir - or, by either an imposed discharge or level as a function of time when the compensating reservoir is implemented.

Making use of computerised analysis of results (special postprocessor and graphical outputs) it was possible to run 43 operating cases within ten days. A typical output is shown in Fig. 5. Series of computations with different load diagrams allowed elaboration of graphs (Fig. 6) illustrating the variation of the above parameters in function of the dimensionless relationship of base to peak flow. 


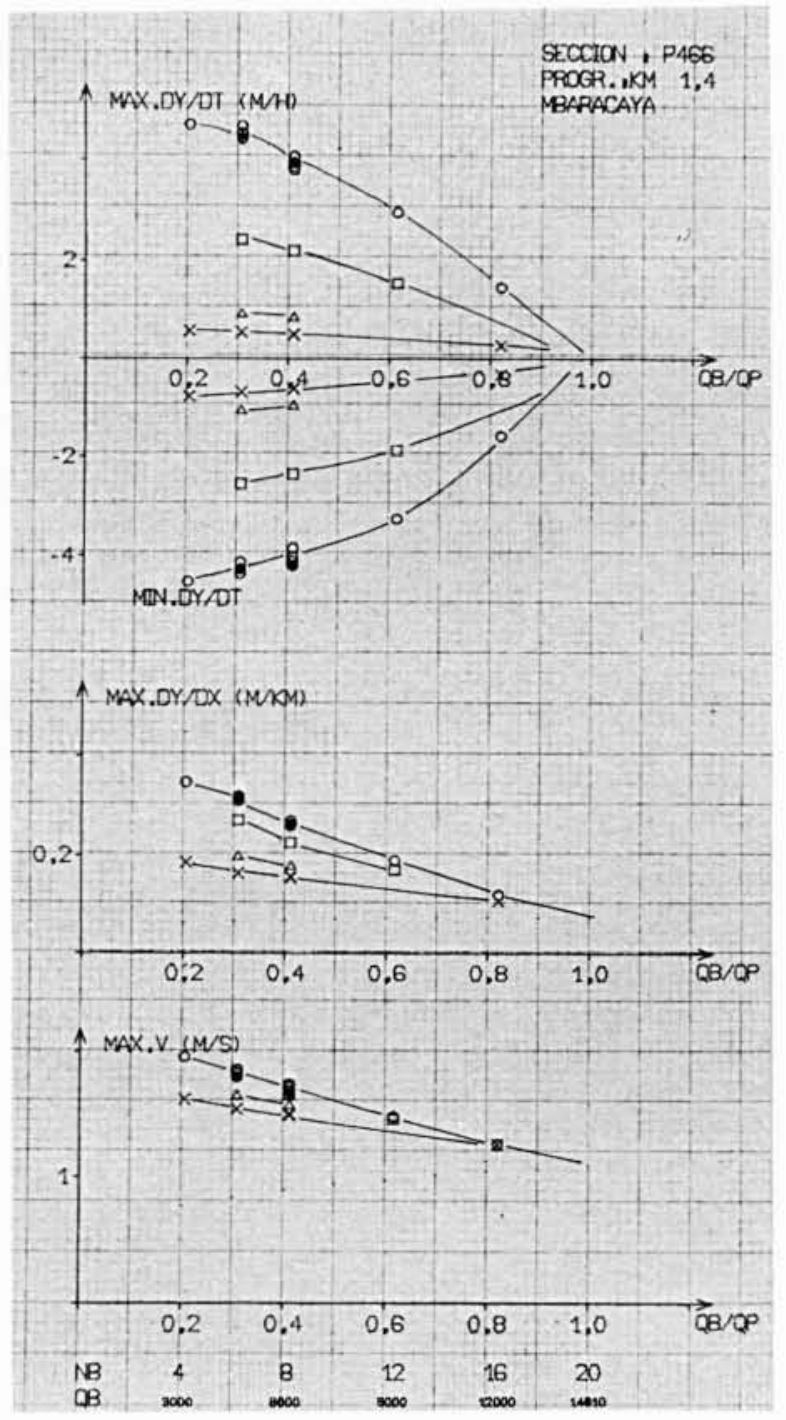

Figure 6. - Synthesis of results for 20 units at P466
This paper further summarizes only two groups of runs, first, the power plant is equipped with 20 turbines $(2700 \mathrm{MW})$ and second, with 22 units (2970 MW) installed.

The first three runs defined by their load diagrams in Table 2 are compatible with each other since their base and peak flows of $4500 \mathrm{~m}^{3} / \mathrm{s}$ and $14610 \mathrm{~m}^{3} / \mathrm{s}$ respectively are identical. The only difference is in the rising and falling limbs of load diagrams: their change from slight to stepwise modulation. By convention $(d y / d t)_{\max }$ is the greatest $d y / d t$ value during the rising stage (positive wave) while $(d y / d t)_{\min }$ is the greatest value during the falling stage (negative wave).

The extreme values of rise and fall velocities are compared in Table 3 for two of the most important cross sections P466, $1.4 \mathrm{~km}$ downstream of the power plant in the main branch and RC4 about $4.2 \mathrm{~km}$ downstream in the San Josemi branch. The maximum value of $5.9 \mathrm{~m} / \mathrm{h}$ at P466 obtained in Run 2 is still not high enough to endanger the navigation.

Run 4 simulates three peaks, and, which is more important, extremely speedy closure of all turbines in 150 seconds. The most striking features of this run observed closely downstream of the power plant are :

- intense fluctuation of water levels;

- decreasing of water depth and reverse flow.

At P466 the fall velocity due to the negative wave arrives at $-9.65 \mathrm{~m} / \mathrm{h}$. At RC4 a very sharp but considerably damped wave of $-3.86 \mathrm{~m} / \mathrm{h}$ is observed. The fluctuations disappear after about 30 minutes. Owing to the complexity of river branches reverse flow of $690 \mathrm{~m}^{3} / \mathrm{s}$ and negative free surface slope up to -0.0005 occur at P466, 12 minutes after starting of turbine closure. The water level further downstream decreases steadily but very slowly, thus, hardly any influence of sections P406, P389 and RCl could be expected.

The slow decrease of depths in the vicinity of the dam allows the opening of the spillway gates up to discharges of $6000 \mathrm{~m}^{3} / \mathrm{s}$ to be reached in 10 minutes. This manœuvre may increase the water stage along the downstream reach by creating a positive wave before the rapid closure of

Table 2

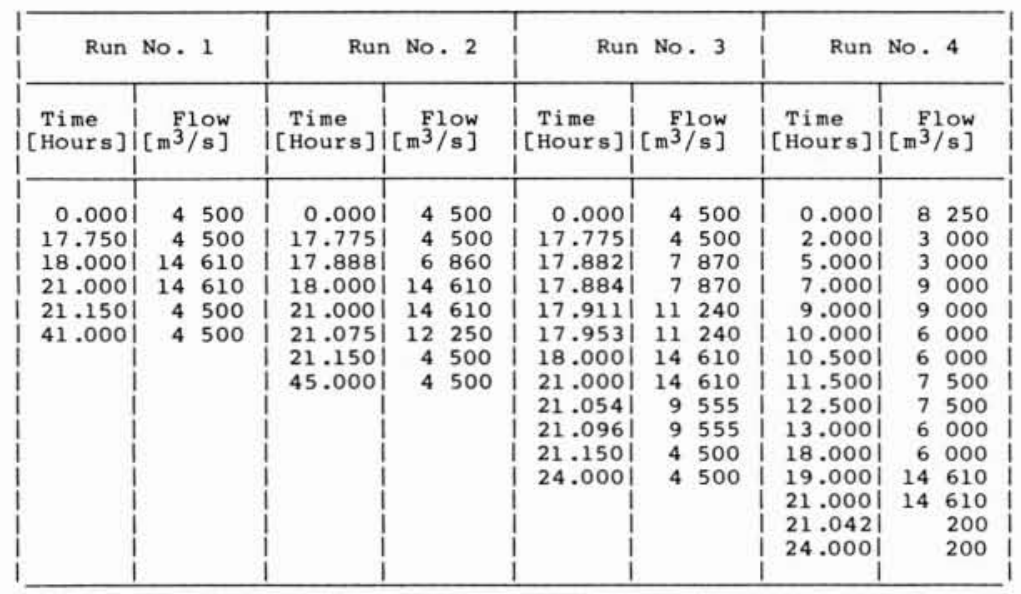


turbines has caused the water depth to decrease to a critical level.

To investigate the influence of the steepness of turbine load diagram on the navigation, Run 5 and 6 are of interest, both showing one day operation with $2970 \mathrm{MW}$ installed. In both cases 6 units are operating in base with $4500 \mathrm{~m}^{3} / \mathrm{s}$ and 22 units in a peak of three hours with $16100 \mathrm{~m}^{3} / \mathrm{s}$. The rising and falling limbs of the load diagram are given by 350 and $525 \mathrm{~m}^{3} / \mathrm{s} / \mathrm{min}$ as moderate, Run 5 , and by 750 and $1125 \mathrm{~m}^{3} / \mathrm{s} / \mathrm{min}$ as steep, Run 6 .

The extreme values of $(d y / d t),(d y / d x)$ and $v$ at the four most important downstream cross sections are illustrated in Table 4.

Runs 5 and 6 clearly show that the steepness of the load diagram considerably influences the rise and fall velocities only in the close vicinity of the power plant.

In order to examine whether the water depth in the downstream reach would fall below $1.80 \mathrm{~m}$, which was given as critical for navigation, the base operation is restricted to 4 units. Assuming a normal daily operation with 22 units i.e., peaking operation limited to 3 hours, the water depth at P443 falls below $1.8 \mathrm{~m}$ at 15.75 hours. The discharge modulation i.e., increase from $3000 \mathrm{~m}^{3} / \mathrm{s}$ (4 units) up to $16100 \mathrm{~m}^{3} / \mathrm{s}$ (22 units) begins at 17.75 hours, causing a positive wave. The water depth remains below $1.80 \mathrm{~m}$ until 19.75 hours when the positive wave arrives at P443. Consequently, by this type of operation the water depth would seriously be influenced in the range of P443 at least 4 hours per day.

In other words, to provide safe navigational conditions, the compensating reservoir has to be implemented before new installations beyond 20 units follow.

\section{Références}

[1] MAHMood (K.) and YevdjeVICH (V.), (1975). Unsteady flow in open channels, chapters 10,14 and 17, Water Resources Publications, Fort Collins, Colorado.

[2] Cunge (J.A.), Holly (F.M.), Verwey (A.), (1980), Practical aspects of computational river hydraulics, Pitman Advanced Publishing Program, Boston-London-Melbourne.

Table 3 - Extreme values of rise and fall velocities

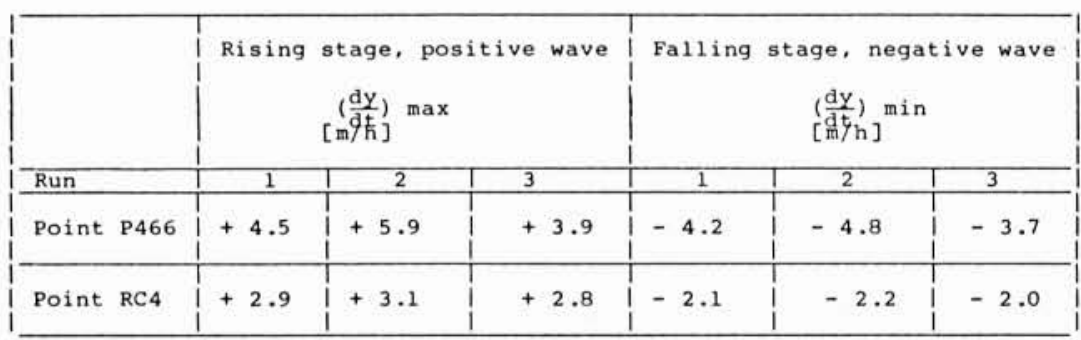

Table 4 - Extreme values of parameters

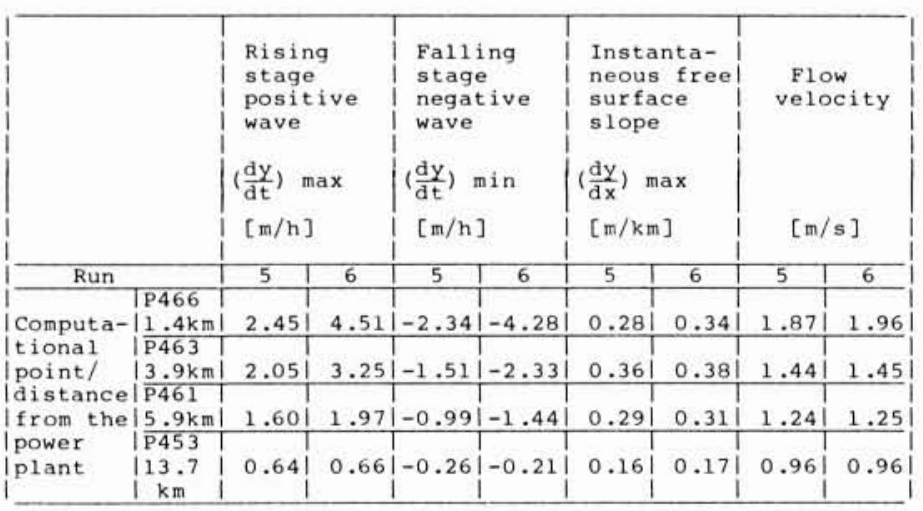


Theorie des Fleuves

Planche IZI,

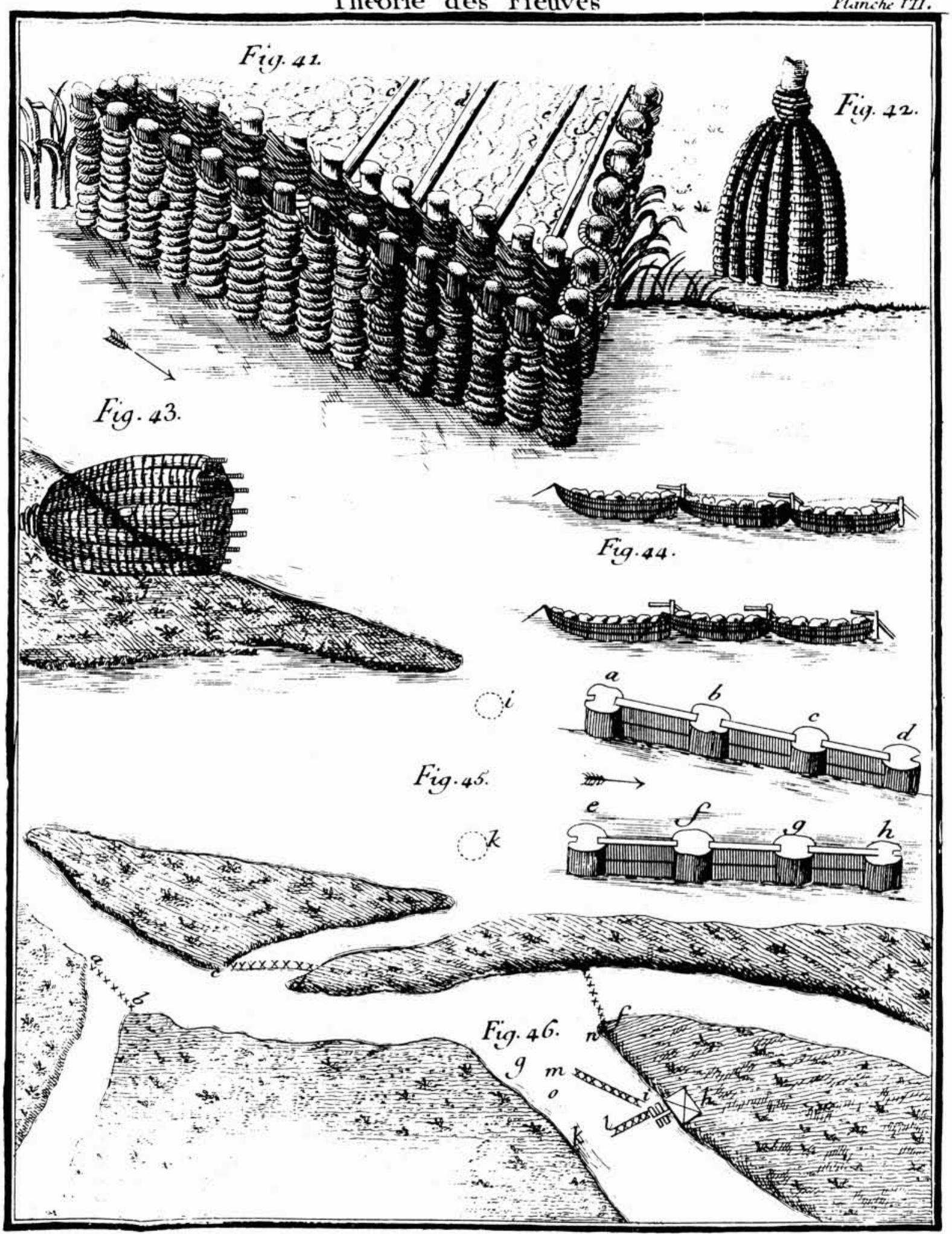

